\title{
An analysis of combustion from a top-lit up-draft (TLUD) cookstove
}

\author{
Cristian Birzer*, Paul Medwell, Josh Wilkey, Tomas West, \\ Matthew Higgins, Gregory MacFarlane and Matthew Read \\ School of Mechanical Engineering, The University of Adelaide \\ *cristian.birzer@adelaide.edu.au
}

\begin{abstract}
It is estimated that three billion people worldwide cook with traditional stoves. These stoves generaly consist of three stones and an open fire, and produce harmful emissions that are known to cause fatal illnesses. Traditional stoves claim the lives of 1.6 million people every year and cause the death of more children under the age of five than any other single cause. In addition, widespread land degradation and deforestation have resulted from inefficient fuel consumption of traditional stoves. This paper presents some results from an extensive investigation into design and experimental evalation of top-lit up-draft (TLUD) microgasifier cookstoves aimed at addressing problems associated with traditional cooking approaches. Results indicate that geometric variations of the stove and fuel size influence burn rates and emissions production, and must therefore be considered for any design and implementation.
\end{abstract}

KEYWORDS: combustion emissions, cookstoves, microgasifier, biofuels

1

\section{INTRODUCTION}

Domestic energy consumption in the developed and developing worlds are vastly different. Currently, the developed world predominantly consumes energy produced from fossil fuels, and to a growing extent, renewable energy sources. In contrast, the developing world is still largely dependent on biomass such as wood, dung and agricultural waste for domestic energy - fuel sources that are typically burned in traditional stoves. Emissions produced by traditional stoves and cooking fires in the developing world cause illness that results in approximately 1.6 million deaths every year (Legros et al, 2009). Due to the high levels of air pollution from these simple stoves, women and young children have an increased risk of acute respiratory infection and lung cancer. Harmful emissions from traditional stoves and cooking fires are reported to claim the lives of more children under the age of five years than any other single cause (Waornat, 2001). Developing affordable systems for cooking that reduce these hazards can help save the lives of millions of people every year.

Three-stone fires are the most commonly used cooking method in developing communities. They consist of three stones placed in a ring on the ground with fuel in the centre of the ring. They are made from and fuelled by material collected in the local environment and rarely incur financial cost. The most commonly used fuel is wood, although dung and agricultural waste are also used. It is known that these stoves are inefficient for fuel consumption and heat transfer. In addition, the emissions produced can be fatal.

The combustion of the biomass fuels, typically used in traditional stoves, can result in the production of harmful emissions. The types and quantities of these emissions are dependent on fuel and the combustion environment, including fuel/air mixing; temperatures; and if the combustion reaction is complete or incomplete. The major products from complete combustion include carbon dioxide $\left(\mathrm{CO}_{2}\right)$, nitrogen oxides $\left(\mathrm{NO}_{\mathrm{x}}\right)$ and large particles including fly ash and salts (Loo \& Koppejan, 2002). Sulphur oxides $\left(\mathrm{SO}_{\mathrm{x}}\right)$, hydrogen chloride $(\mathrm{HCl})$ and heavy metals may also be present, subject to the fuel. Incomplete combustion generaly results from inadequate mixing of fuel and oxygen, low combustion temperatures and short residence times. In addition to the aforementioned emissions, incomplete combustion includes carbon monoxide (CO), volatile organic compounds (VOC) and fine particles (PM2.5-10) (Loo \& Koppejan, 2002). Emissions from incomplete combustion of biomass are of particular concern for both adverse health effects and climate change (Jetter \& Kariher, 2009).

Dung is a commonly used biomass fuel. Dung produces higher amounts of poisonous $\mathrm{CO}$ emissions compared to wood and agricultural residues. The release of $\mathrm{CO}$ is one of the most hazardous products 

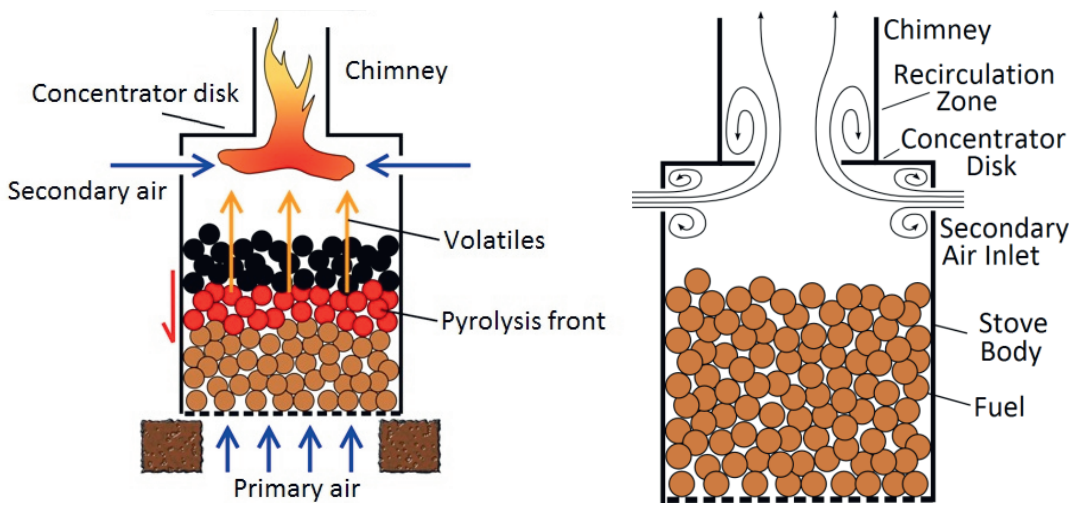

Figure 1: Schematic diagrams of (left) the naturaldraft combustion process and (right) the fluid flow patterns generated by the use of a concentrator disk in a TLUD stove.
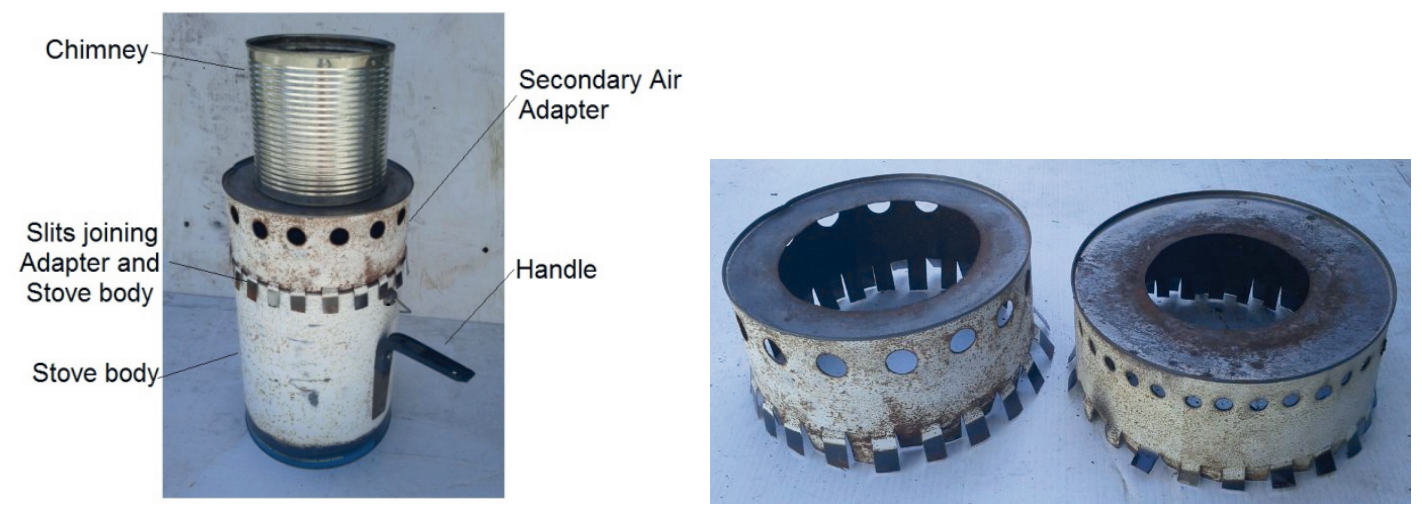

Figure 2: $\quad$ Photos of (left) the assembled TLUD stove used for experiments and (right) two adaptors for the TLUD stove. These adaptors have different concentrator disk diameters (the large hole in the centre of each adaptor) and different secondary air inlet hole sizes and numbers.

from biomass combustion stoves (Maroni et al, 1995). The production of CO is directly related to the burn rate (Bhattacharya \& Salam, 2002). Stove users generally utilise burn rate to control the power output of the stoves with an increase in burn rate resulting in an increase in power output (Kandpal et al, 1994). Therefore, burn rate is of critical importance in any stove design.

Evidence indicates that emissions from inadequate biomass stoves are linked to acute lower respiratory infection, chronic obstructive pulmonary disease and lung cancer in women and children (Desai et al, 2004). Consequently, many significant health, productivity and environmental benefits may result from replacing traditional cooking fires with modern cooking stoves (Heltberg, 2004). Despite this, approximately 3 billion people in developing countries still rely on traditional stoves (Legros et al, 2009); this is due to the expense and unavailability of modern sources (WHO, 2002). Due to limited budgets, solid fuels such as wood, crop residue and animal dung are used throughout the developing world (Rao, 1985). Of the people who rely on traditional sources to meet their cooking needs, approximately 2.6 billion people use biomass sources while 400 million use coal (Legros et al, 2009). Development of the design of biomassfuelled cookstoves has the potential to improve the lives of over a third of the world's population.

Compared with some improved stoves, three-stone fires produce $15-30 \%$ more particulate matter in the form of PM10 and PM2.5 particles (Naeher et al, 2000) and release more emissions of CO (Jetter \& Kariher, 2009; MacCarty et al, 2008). However, incorrect usage of some "improved" stoves can result in lower efficiencies and an increase in some harmful emissions. There are no known published results from the systematic study of the development of improved cook stoves.

One particular stove design that can be used to potentially reduce harmful emissions production from solid-fuel combustion is a top-lit up-draft (TLUD) microgasifier stove (Figures 1 and 2). The combustion process of a TLUD stove can produce fewer harmful emissions and preserves the charcoal as biochar (an organic soil enhancer) (Anderson, 2009). This technology can be applied to a stove to burn almost any solid biomass fuel, including wood pellets, nut shells, crop residues, textile waste and animal dung, thereby reducing the depletion of wood resources (Anderson \& Roth, 2011). Unfortunately, 
insufficient scientific information is available for design optimisation of these types of stoves.

The combustion process of a TLUD stove is shown diagrammatically in Figure 1. These stoves utilise pyrolysis (a thermo-chemical decomposition of biomass at elevated temperatures in a low oxygen environment (Roth, 2011)) to separate solid biomass into charcoal and volatiles. Once the volatiles have been released, they travel up through the stove. Air is drawn in through the air inlets and enters the fuel chamber as either primary air that travels up through the packed fuel, or secondary air that mixes with volatiles before combustion.

The flame is held above the biomass at the point of mixture with secondary air and travels up through the chimney. A pressure drop generated by the chimney results in air being drawn into the stove via the primary and secondary air inlets. The flow rates through these two flows are related to chimney geometry. Additionally, it is postulated that the use of a concentrator disk can be used to increase turbulence and hence improve mixing of air and fuel. The concentrator disk consists of an orifice plate with a hole in the centre (refer to Figure 1). In the current experiment, the diameter of the hole is a variable. Although it is known that the optimal mixture of secondary and primary air for combustion is approximately 4:1 (MacCarty et al, 2008) and it is evident that the chimney design plays an important role in TLUD combustion, there is no known published systematic scientific study of TLUD chimney designs and the impact on combustion and emissions.

Microgasifiers, such as the TLUD, are able to reduce fuel consumption by up to $75 \%$ (compared to a three-stone fire) and lower emissions compared with other designs (Servals Automation, 2011). However, this requires optimal design of stove geometry as well as fuel preparation (Roth, 2011). Fuel preparation requires fuel pieces to be small enough to allow for complete pyrolysis, but large enough to enable primary air flow through the packed fuel and different fuels require different preparation. Poor stove design or fuel preparation can result in incomplete combustion and lower efficiency. However, specific information on stove geometry and fuel size on stove performance is limited. Furthermore, despite the importance of TLUD design on emissions production, the scientific analyses are limited. For the current study, analysis is focused on $\mathrm{CO}_{2}, \mathrm{CO}$ and $\mathrm{NO}_{\mathrm{x}}$ emissions.

The motivation of the current work is focused on developing affordable and sustainable clean-burning cooking systems for the developing world. The aim of the current paper is to further the knowledge of TLUD designs for improved combustion. Specific focus is given to chimney geometry (height and diameter) and fuel size on burn rate and emissions production. Experiments were conducted to measure the production of $\mathrm{CO}_{2}, \mathrm{CO}$ and $\mathrm{NO}_{\mathrm{x}}$ and enable estimates of fuel burn rates.

\section{EQUIPMENT}

\subsection{TLUD stove design}

A TLUD stove with various chimney configurations is used for the experiments. These variations include the chimney height, chimney diameter and concentrator disk diameter. For testing of emissions, a comparison is made to a traditional three-stone stove. The TLUD stove is made from readily available recycled parts, in order to ensure that the final design can be made at little, if any, monetary cost. The stove body of the TLUD is made from a $10 \mathrm{~L}$ paint tin (donated by Solver Paints) with holes drilled into the base as the primary air inlet. The stove adaptor (see Figure 2) is made from a second $10 \mathrm{~L}$ paint tin. The diameter $(D)$ of the TLUD is $200 \mathrm{~mm}$. The chimney is made from either tomato or baked bean cans, in order to vary chimney geometry without the need for sheet metal fabrication. Figure 2 show images of the assembled TLUD stove and the adaptors, respectively.

\section{$2.2 \quad$ Fuel}

To assess the burn rates for various chimney configurations, in order to identify an optimal TLUD design, wood pellets were used as the fuel. This was to provide consistency of fuels for various experiments, compared with using dung. The wood pellets used were obtained from Pellet Heaters Australa (PHA) with details listed in Table 1.

Table 1: Wood pellet specifications used for preliminary TLUD stove testing.

\begin{tabular}{|l|l|}
\hline Size & $6.5 \mathrm{~mm}$ \\
\hline Moisture Content & $<8 \%$ \\
\hline Heating Value & $18,770 \mathrm{~kJ} / \mathrm{kg}$ \\
\hline Bulk Density & $>672 \mathrm{~kg} / \mathrm{m}^{3}$ \\
\hline Ash Content & $<1 \%$ \\
\hline Raw Material & Australian Hardwood \\
\hline
\end{tabular}

The comparison of an optimised TLUD stove is made to that of a three-stone fire with dung as fuel. The regional focus of the project is the Nepalese Terai region, which typically uses buffalo dung. Due to the limited available resources of buffalo dung for the current experiments, Angus cattle dung was used as a surrogate. Nepalese buffalo predominately eat grass, and occasionaly hay and other agricultural waste (Tuladhar, 2010). Similarly, the Angus cattle that produced the dung used in testing were primarily grazing animals, their diet consisting of grass and hay. Fresh cow dung was collected from one particular 

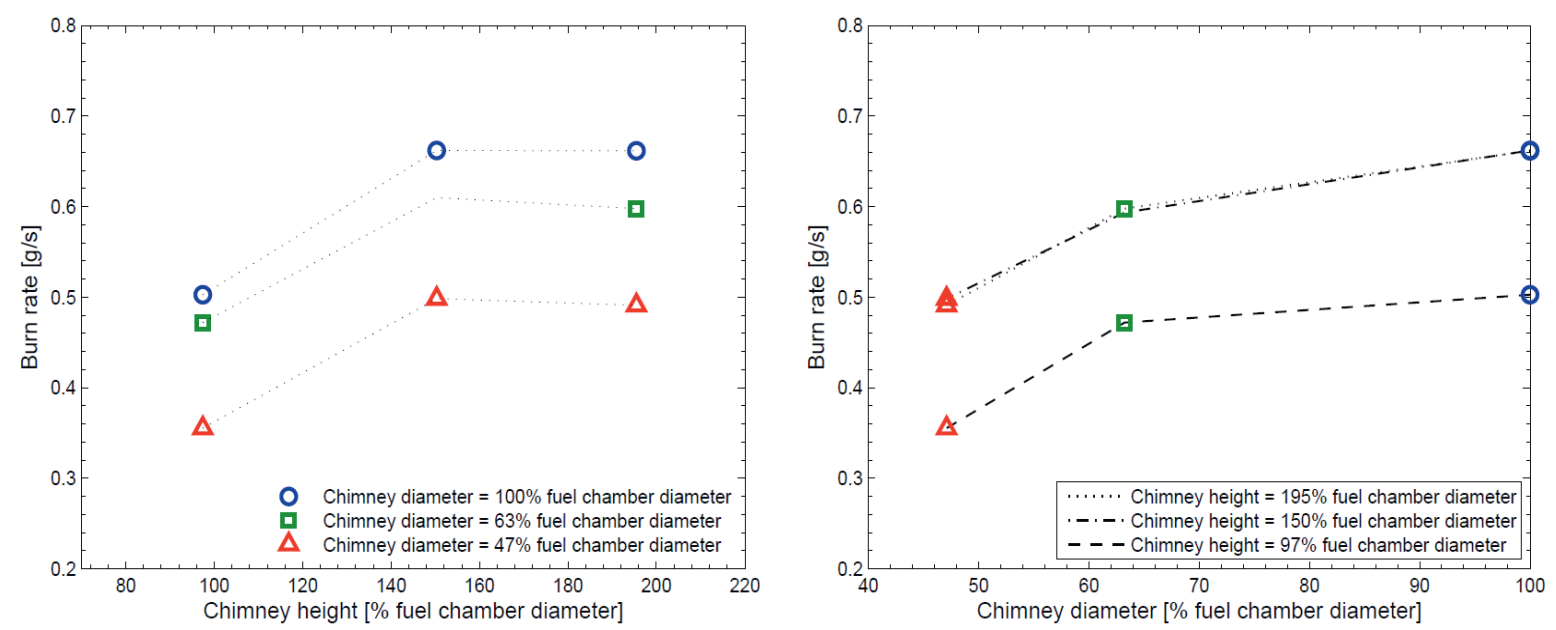

Figure 3: Average burn rate of a wood pellet burning TLUD stove as a function of (left) chimney height and (right) chimney diameter, based on a chamber diameter of $D=200 \mathrm{~mm}$.

farm. The dung was formed into palm-sized patties and left to dry for a period of two weeks to be consistent with Nepalese dung preparation. The patties were then cut to various sizes in order to assess the influence on fuel piece size for testing in the stove.

\section{RESULTS AND DISCUSSION}

\subsection{Burn rate and chimney geometry}

The burn rate of fuel is the rate at which the solid fuel loses mass during a stove's operation. It is calculated by dividing the lost mass of the fuel by the burn time; the time from when the starter fluid ${ }^{1}$ is ignited to when the stove is snuffed. Burn rate provides an indication of the natural draft induced through the stove, and the pyrolysis and combustion processes which occur in the fuel bed and at the top of the fuel chamber. Understanding the trends in the burn rate with changes in geometric parameters provided a basis on which to further develop stove designs.

For the experiments conducted to assess burn rate of fuel for variations in TLUD geometry, $500 \mathrm{~g}$ of wood pellet fuel (ignited using $50 \mathrm{~g}$ of ethanol) was used. The flame colour during combustion of volatiles is a bright yellow / orange. When the flame turns blue, it indicates that the majority of the volatiles have been released and that char combustion dominates. At this point, the TLUD is no longer operating within its design window, the stoves were therefore snuffed when a blue flame appeared. After cooling, the remaining biomass was weighed.

Figure 3 shows results of the burn rate of fuel (g/s) for three separate chimney diameters and three chimney heights. The chimney geometry is presented relative

${ }^{1}$ Although starter fluid is not readily accessible in developing communities, for the purposes of experimental repeatability it is necessary to add starter fluid as this helps ensure reliable ignition and thus a reliable measure of the start of the combustion cycle. The small quantity that is added has negligible effects on the performance or measurements of the stove. to the stove chamber diameter, $D=200 \mathrm{~mm}$. There is no concentrator disk for these results. Although there are only a small number of data points, it can be seen that the burn rate initially increases and then plateaus at a chimney height of approximately $1.5 \mathrm{D}$. This is true for all chimney diameters, although the maximum power output occurs at a chimney diameter equal to that of the chamber diameter. It is known that the burn rate is a function of air flowrate, which is driven by the pressure differential generated by the chimney: the greater the pressure differential the greater the expected flow rate and hence greater the burn rate. A taller chimney may be expected to have a greater pressure differential and subsequently greater burn rate. However, viscous losses are also increased with chimney height. The optimal balance of pressure differential and viscous loss occurs when the chimney height is somewhere between $D$ and $1.5 D$. With the limited data currently available, the optimal chimney height is seen to be at $1.5 D$ and width of $D$.

The proposed purpose of the concentrator disk is to increase mixing of fuel and secondary air via enhanced turbulence, and hence improve combustion (see Figure 1). Figure 4 shows a plot of the burn rate of fuel (g/s) for four different concentrator disk diameters when using chimney width and height of $D$. It is evident from Figure 4 that, for this set of experiments, a concentrator disk reduces the burn rate (and therefore power output). This indicates that pressure drop and hence lower air flowrate has a greater impact than enhanced mixing from turbulence in the recirculation zone of the concentrator disk. It is important to note that a concentrator disk diameter of $0.7 D$ generates the same burn rate as a concentrator disk diameter of $D$ (i.e. no disk or restriction), suggesting that there is some tolerance to minor flow restrictions. Referring back to Figure 3 (right), if the chimney diameter is $0.63 D$ (approximately $0.7 D$ ), there is a reduction in burn rate of approximately $10 \%$ compared with the 


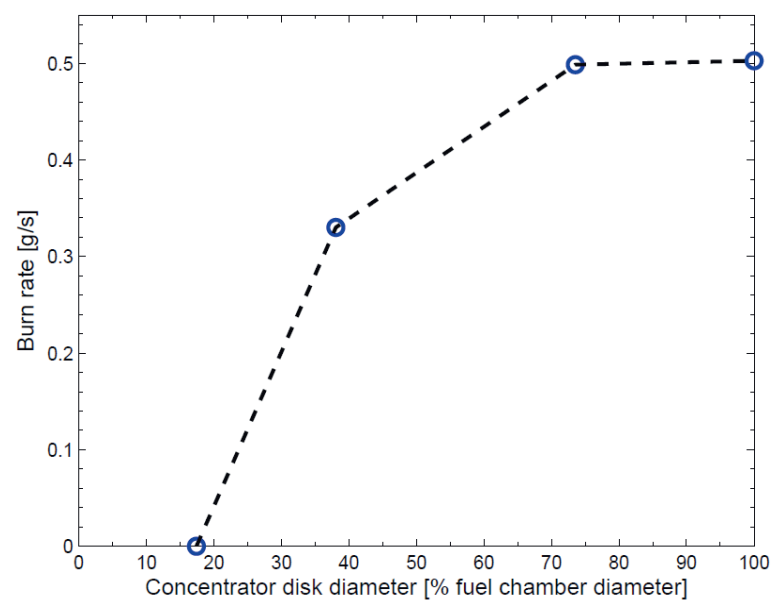

Figure 4: $\quad$ Burn rate (grams of fuel consumed per second) of a TLUD stove burning wood pellets for different concentrator disk diameters (normalised to the fuel chamber diameter, $D=200 \mathrm{~mm})$. Chimney diameter and height constant at $D$ and $1.5 D$ respectively.

$1.0 D$ chimney diameter case. The significance of this finding is that minor obstructions have little influence on burn rate or power output of a TLUD cookstove.

\subsection{Fuel size}

As detailed in section 1, the fuel used in a TLUD needs to be prepared appropriately. If fuel pieces are too small they will block the primary air flowrate, preventing pyrolysis and extinguishing the flame. If fuel pieces are too large, then the core of each fuel piece will not devolatilise completely, thereby wasting fuel. Furthermore, the optimised balance of fuel and air will not be maintained, reducing the stove efficiency.

To assess fuel size, standard water boiling tests (WBT) were conducted. During these tests the TLUD is ignited using $1800 \mathrm{~g}$ of dung and $50 \mathrm{~g}$ of ethanol. Once the flame is established and stabilised, a $2 \mathrm{~L}$ pot of water is placed above the stove and heated until the flame changed colour from yellow/orange to blue, indicating combustion of the char and incorrect TLUD operation. During operation of a TLUD the change of flame colour from yellow to blue is associated with an increase in $\mathrm{CO}$ emissions. During the tests, water temperature measurements are taken. After the test and once cooled, the weight of remaining water and char are recorded.

Figure 5 shows a plot of temperature of water in a WBT versus cooking time for four different sizes of dung fuel. In these experiments, a commercial off-the-shelf TLUD of similar size (Champion) was used for convenience and ensures a direct link of the results to communities currently relying on these stoves. An image of the Champion TLUD is shown

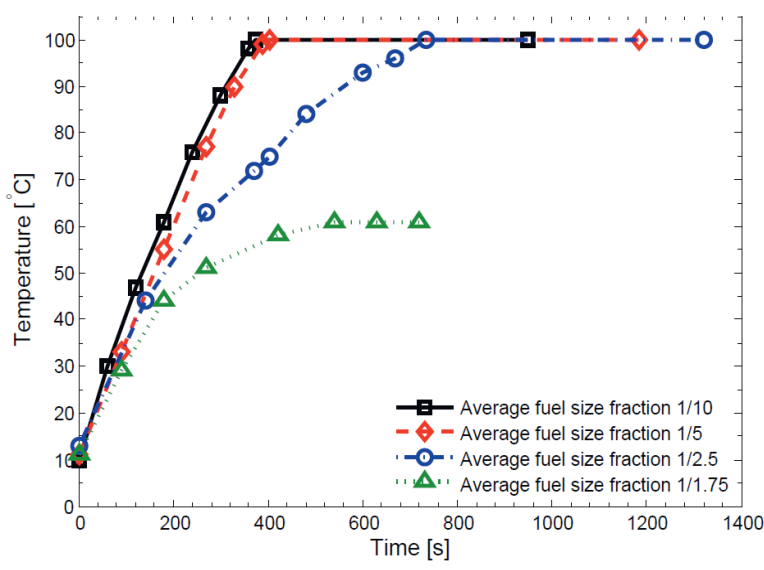

Figure 5: Temperature profiles from WBT conducted for different fuel size ratios (relative to the diameter, $D=200 \mathrm{~mm}$ ) of cow dung in a TLUD stove.

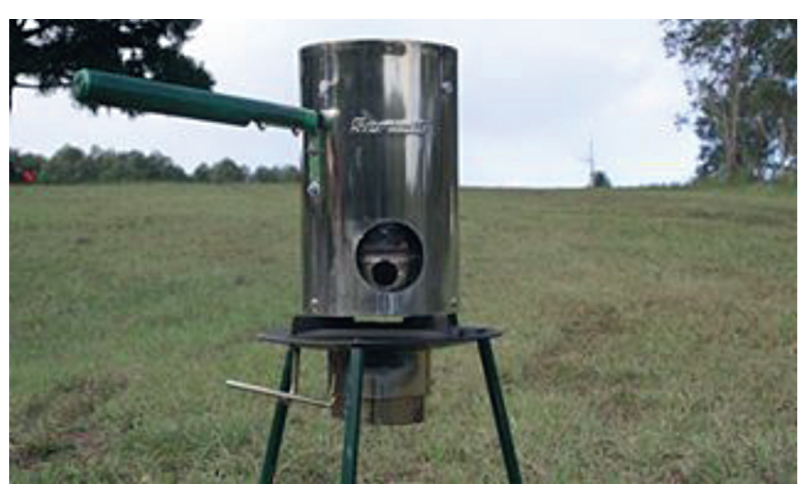

Figure 6: Example of a commercial off-the-shelf Champion TLUD stove (Cooke, 2013).

in Figure 6. The fuel sizes were sized as fractions of the chamber diameter, $D=200 \mathrm{~mm}$.

The results from Figure 5 indicate that the larger the fuel pieces, the longer it takes to boil water. The pressure drop across the chimney is insufficient to entrain the required primary air through the packed fuel, thereby limiting pyrolysis and the fuel / air mixture ratio. The poor performance of the stove with large size fuel pieces is such that water does not heat to above $60^{\circ} \mathrm{C}$.

The smaller fuel sizes $(D / 10$ and $D / 5)$ both boil water at similar rates. However, this does not take into account the total burn time or burn rate. Figure 7 shows plots of the fuel size in relation to the burn rate and thermal efficiency. These results are from a modified WBT where only $1 \mathrm{~L}$ of water is boiled, rather than the standard $2 \mathrm{~L}$. This was done to conserve total fuel usage. From these results it can be seen that the total burn time of fuel sizes of $D / 5$ have a longer burn time compared with sizes $D / 10$ and hence a higher thermal efficiency. Here, the thermal efficiency $(\eta)$ is calulated as:

$\eta=\frac{H_{t}+H_{v}}{H_{f}}$ 

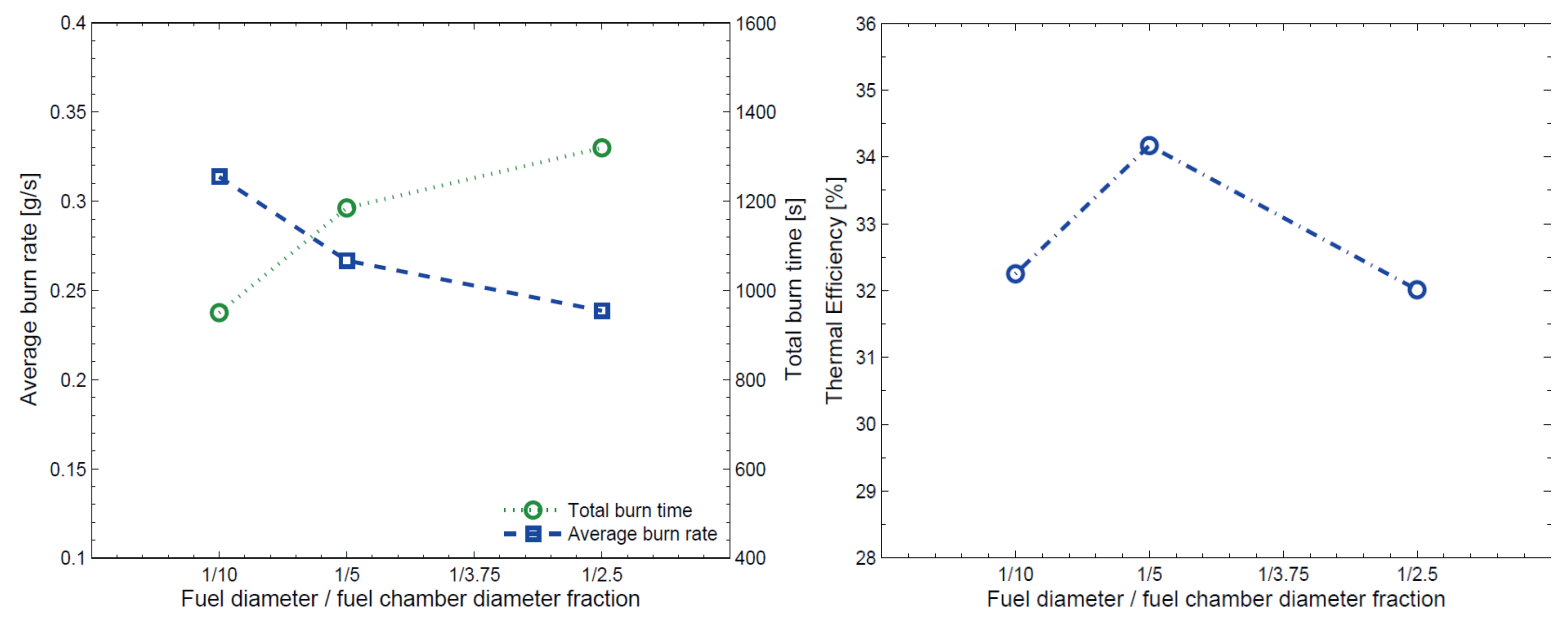

Figure 7: $\quad$ Results from the modified WBT for different size cow dung fuel pieces in a Champion TLUD stove: (left) burn rate and boil time; (right) thermal efficiency.

where $H_{t}$ is energy from temperature rise, $H_{v}$ is the energy from evaporation and $H_{f}$ is the energy derived from the fuel. $H_{t^{\prime}} H_{v}$ and $H_{f}$ are determined from the following:

$H_{t}=C_{p} m_{w} \Delta T$

$H_{v}=L m_{v}$

$H_{f}=\Delta m_{f} L H V$

where $C_{p}$ is the specific heat of water $(4.18 \mathrm{~kJ} / \mathrm{kg}), L$ latent heat of vapourisation $(2260 \mathrm{~kJ} / \mathrm{kg}), m_{w^{\prime}}, m_{v^{\prime}}, m_{f}$ are the masses of water at the start of the experiments, water evaporated and fuel burnt respectively, $\Delta T$ is the change in temperature $\left({ }^{\circ} \mathrm{C}\right)$ and $L H V$ is the lower heating value of fuel $(11,000 \mathrm{KJ} / \mathrm{kg}$ for dung as presented in Kandpal et al, 1994).

\subsection{Emissions production}

Measurements of $\mathrm{CO}, \mathrm{CO}_{2(\mathrm{eq})^{\prime}}$ and $\mathrm{NO}_{\mathrm{x}}$ emissions from both the TLUD stove and three-stone fire using dung fuel were made using a Testo ${ }^{\mathrm{TM}}$ XL350 gas analyser at approximately one metre above the stove. Both tests were run with $500 \mathrm{~g}$ of the cow dung (plus $20 \mathrm{~g}$ of ethanol) under an extraction hood and without a cooking pot. While the extraction hood and lack of cooking pot may affect the overall performance of the stoves, it is assumed that the general trends observed in these experiments are reliable and consistent with the overall performance of the stoves. The time-averaged results from these tests are presented in Table 2.

In Table 2 it can be seen that the TLUD produces just over half the $\mathrm{CO}$ emissions compared with the three-stone fire. Emission of CO correlates to incomplete combustion and therefore it is clear that the three-stone fire burns inefficiently. The levels of $\mathrm{CO}$ produced from the three-stone fire are greater than allowable levels dictated by WHO standards. The specific design of a three-stone fire may be expected to have some influence on the absolute emissions. Here, the three-stone fire was built using regular house bricks rather than stones. Nonetheless, the general trends observed here are representative of typical emissions from a fire in comparison with a TLUD stove.

The TLUD produces much higher levels of $\mathrm{NO}_{X^{\prime}}$ and $\mathrm{CO}_{2(\mathrm{eq})^{\prime}}$ but the burn rate of the TLUD is much higher as well. As both $\mathrm{NO}_{X}$ and $\mathrm{CO}_{2(\mathrm{eq})}$ correspond to the burn rate, these higher values are expected. Nonetheless, although the high $\mathrm{NO}_{x}$ values are less than the maximum 24-hour exposure levels dictated by the WHO, they are still significant. Any stove burning high-nitrogen fuels, such as dung, must therefore limit burn rates to reduce $\mathrm{NO}_{X}$ production.

Table 2: Three-stone fire and TLUD stove emissions testing results. Results are time averaged and taken at a height of approximately $1 \mathrm{~m}$ above the cookstove.

\begin{tabular}{|l|c|c|c|c|c|c|c|}
\hline Stove & $\begin{array}{c}\mathrm{CO} \\
(\mathbf{p p m})\end{array}$ & $\begin{array}{c}\mathrm{CO}_{2(\mathrm{eq})} \\
(\mathbf{\%})\end{array}$ & $\begin{array}{c}\mathbf{N O}_{\mathrm{x}} \\
(\mathbf{p p m})\end{array}$ & $\begin{array}{c}\mathrm{Burn} \text { rate } \\
(\mathbf{g} / \mathbf{s})\end{array}$ & $\begin{array}{c}\mathrm{CO} \\
(\mathbf{p p m} / \mathbf{g} / \mathbf{s})\end{array}$ & $\begin{array}{c}\mathrm{CO}_{2(\text { eq) }} \\
(\mathbf{\%} / \mathbf{g} / \mathbf{s})\end{array}$ & $\begin{array}{c}\mathrm{NO}_{\mathrm{x}} \\
(\mathbf{p p m} / \mathbf{g} / \mathbf{s})\end{array}$ \\
\hline $\begin{array}{l}\text { Three-stone } \\
\text { fire }\end{array}$ & 95.4 & 0.246 & 12.4 & 0.221 & 432 & 1.11 & 56.2 \\
\hline $\begin{array}{l}\text { Optimised } \\
\text { TLUD }\end{array}$ & 49.3 & 0.830 & 54.3 & 0.875 & 56.4 & 0.949 & 62.1 \\
\hline
\end{tabular}


As the burn rates (fuel consumption rates) are different they are not necessarily directly comparable. Therefore, the normalised production rates of $\mathrm{CO}$, $\mathrm{CO}_{2(\mathrm{eq})}$ and $\mathrm{NO}_{\mathrm{X}}$ are also presented in Table 2. These values (in ppm/g/s) show that the levels of $\mathrm{NO}_{X}$ and $\mathrm{CO}_{2(\mathrm{eq})}$ are similar - within $15 \%$. However, the normalised values of $\mathrm{CO}$ highlight the significantly higher values produced by the three-stone fire. As CO has been identified as a significantly more dangerous emission than the others investigated, it is clear that an optimised TLUD provides a suitable alternative, if burn rate and therefore power output are controlled. This is an operational issue, rather than technical one.

\section{CONCLUSION}

A modified TLUD stove has been produced, tested and compared with a traditional three-stone fire. The results indicate that variations in geometry of the TLUD chimney are essential to ensure improved combustion. Results also show that when burning dung, the TLUD with optimised chimney geometry, is far superior to a three-stone fire in regards to $\mathrm{CO}$ emissions, but due to the higher burn rate, can produce higher levels of $\mathrm{NO}_{X^{\prime}}$ and $\mathrm{CO}_{2(\mathrm{eq})}$. Results also indicate that fuel preparation is important to ensure correct TLUD operation.

\section{REFERENCES}

Anderson, P., 2009, 'Construction plans for the Champion-2008 TLUD gasifier cookstove', edition 1.1.

Anderson, P. \& Roth, C., 2011, 'Practical realties of TLUD micro-gasifier cookstoves', PCIA Forum.

Bhattacharya, S. \& Salm, P. 2002, 'Low greenhouse gas biomass options for cooking in developing countries', Biomass and Bioenergy, 22, pp. 305-317.

Cooke, D., 2013, Biochar Project, http:// biocharproject.org/charmasters-log/tlud-biocharstove-sale-biochar-industries /, accessed 11 June 2013.

Desai, M., Mehta, S. \& Smith K., 2004, 'Indoor smoke from solid fuels: assessing the environmental burden of disease at national and local levels', World Health Organization.

Heltberg, R., 2004, 'Fuel switching: evidence from eight developing countries', Energy Economics, 26, pp. 869-887.

Jetter, J. \& Kariher, P., 2009, 'Solid fuel household cook stoves: characterization of performance and emissions', Biomass and Bioenergy, 33, pp. 294-305.
Kandpal J., Maheshwari, R. \& Kandpa, T., 1994, 'Comparison of $\mathrm{CO}, \mathrm{NO}$ and $\mathrm{HCHO}$ emissions from biomass combustion in traditional and improved cookstoves', Energy, Vol. 19, No. 11, pp. 1151-1155.

Legros, G., Havet, I., Bruce, N., Bonjour, S., Rijal K., Takada, M., \& Dora, C., 2009, 'The energy access situation in developing countries: a review focusing on the least developed countries and Sub-Saharan Africa', World Health Organization.

Loo, S. \& Koppejan, J., 2002, ‘Handbook of biomass combustion and co-firing', Twente University Press.

MacCarty, N., Ogle, D., and Still, D., 2008, 'A laboratory comparison of the global warming impact of five major types of biomass cooking stoves', Energy for Sustainable Development, Vol. 7, No. 2, pp. 5-14.

Maroni, B., Seifert, B., Lindval, T., Maroni, M., Seifert, B., \& Lindval, T., 1995, 'Indoor air qualty - a comprehensive reference book', Elsevier Science.

Naeher, L., Leaderer, B., \& Smith, K., 2000, 'Particulate matter and carbon monoxide in highland Guatemala: indoor and outdoor levels from traditional and improved wood stoves and gas stoves', Indoor Air, 10, pp. 200-205.

Rao, K., 1985 'Domestic cook stove of superior performance for solid fuels', Journal of the Institution of Engineers (India), Mechanical Engineering Division, 65, pp. 100-102.

Roth, C., 2011, 'Micro-gasification: cooking with gas from biomass', Gasification, 1, pp. 8-35.

Servals Automation Pty Ltd., 2011, TLUD Gasifier Stoves - A Wood Stove with a Difference, 9 May 2011. http://servalsgroup.blogspot.com/2009/05/tludgasifier-stoves-wood-stove-with.html

Tuladhar, S., 2010, 'Research on dung-based burning cookstove for the southern belt of Nepal', EWB Research Paper, September 2010.

Waornat, M., 2001, 'Polycyclic aromatic hydrocarbons identified in soot extracts from domestic coal-burning stoves of Henan Province, China', Environmental Science \& Technology, 35, pp. 1943-1952.

World Health Organization, 2002, 'Addressing the links between indoor air pollution, household energy and human health', World Health Organization, Washington Consultation. 
